\title{
CYBERSPACE: GLOBAL PUBLIC GOODS?
}

\section{Gabriela Žáková*}

\begin{abstract}
Cyberspace has become an indispensable part of our everyday lives. Due to the Internet of Things, it has permeated the whole of society. Nevertheless, cyberspace on its own still tends to be neglected in academia, especially in social sciences. This article aims to contribute to the debate over whether cyberspace may be labelled as global public goods. First, the essential economic theories dealing with public goods are presented forming a solid basis for the subsequent analysis and stating the basic conditions for the evaluation of cyberspace as global public goods. Second, a basic cyberspace model is introduced dividing it into three different layers - the physical layer, the application level, and the level of information. Third, an analysis is conducted testing each layer for the legitimacy of global public goods categorisation. Fourth, a final synthesis provides the answer to the question of whether cyberspace can be categorised as global public goods. Based on the findings in the analytical part of this paper, it has been concluded that cyberspace may be, although with several reservations, categorised as global public goods.
\end{abstract}

Keywords: cyberspace, global public goods, impure public goods, Internet, information, technology, communication, Internet of Things

JEL Classification: H41, O14, O33, D83

\section{Introduction}

The origins of cyberspace can be dated back to the beginning of the Cold War when the first request for data transmission between computers was made. The aim was to create an independent communication network that would not be operated as control nodes as were telephone exchanges which would be vulnerable in the event of a military conflict. The development of information technology led to growing requirements for data transmission between mutually connected computers and resulted in the development of communication protocols and the creation of supernetworks. Nowadays, cyberspace is an indispensable part of our lives, at least in the developed world. A considerable number of economic transactions are conducted in cyberspace and virtual currencies have been traded massively - especially the bitcoin.

Nevertheless, cyberspace remains a rather unexplored phenomenon by economic scholars despite its importance. Even though the number of articles dealing with cyberspace is rising, cyberspace has tended to be rather neglected by researchers in this field. There

* Faculty of International Relations, University of Economics, Prague (gabriela91@gmail.com). 
has been a debate considering the characteristics of cyberspace. Some authors tend to consider cyberspace as public goods, yet others disagree with this notion. This article poses a question whether we can label cyberspace as global public goods, impure public goods, or private goods. To answer this question, it is necessary to present the public goods theories and identify the criteria to this question. Consequently, a simplified model of cyberspace will be introduced, which enables an analysis of its layers. Each layer of cyberspace will be questioned for the possibility of it being public goods. To conclude, a synthesis of the knowledge acquired will be conducted and the answer to the question of whether we can term cyberspace public goods or not will be stated. Thus, this paper can contribute to a better understanding of cyberspace from an economic point of view. An optimal economic policy towards cyberspace can only be adopted if we are able to identify the economic features of cyberspace and claim whether it can be managed as pure global public goods, impure public goods, or private goods.

\section{Literature Review}

\subsection{Global Public Goods}

The essential criteria to distinguish goods as public goods are accessibility and allocation. Public goods are goods that can be used by more consumers at once with no effect on the utility of other consumers (Nilsen, 2010). On the other hand, private goods can be limited to a certain number of users and the consumption of a consumer leads to a decrease of the utility of other consumers (Kaul, 2009). Apart from pure public and pure private goods, there are also impure public goods. Furthermore, we can also classify the goods by territoriality into regional, international and global goods (Te Velde, Morrissey and Hewitt, 2002) according to the scope of impact.

Paul Samuelson (1954) was the first to address collective goods when he contrasted them with private goods in his model. The essential feature of these goods is that all consumers can use them collectively. At the same time, the consumption of collective goods does not diminish the available utility to other consumers and thus the goods are nonrival in consumption. Musgrave (1959) defines public wants as needs that can be met by a community of individuals rather than only individuals. The level of individual satisfaction depends on the level reached by society's welfare, and not on individual contributions.

Head (1962) expanded on both authors and fused Samuelson's model of collective goods with Musgrave's model of public wants. The model of public goods became the synthesis of both these models and the features of public goods were stated for the first time: (1) nonrival consumption and (2) non-excludability, i.e. impossible to exclude individual consumers from the consumption of the goods. There are two conditions stemming from his model: (1) public goods available to a consumer are available to other consumers at the same price and quantity, and (2) their general availability fails to exclude those consumers who do not pay for their consumption.

The issue of public goods is closely intertwined with the issue of externalities. Externalities appear when production or consumption of a subject causes unintended costs or benefits to other subjects, although those who caused the costs or gained the benefits failed to pay for them (Macáková, 2006). Externalities can be divided into positive 
and negative. Positive externalities bring additional benefits to other subjects who do not pay for them. On the contrary, the negative externalities bring additional costs to those who did not cause them. With this effect, market forces lead to a market price which does not fully reflect social costs and benefits, and presents a market failure case.

The pioneers of the externalities debate were Henry Sidgwick and Arthur C. Pigou. While Sidgwick expressed the thought of spillover costs and benefits, Pigou developed the thought and conceptualised the idea of society's welfare (McConnell, Brue and Flyn, 2008). A great share of today's debate is focused on the management of indirect costs and benefits which appear as a side effect of economic activity and which cannot be attributed to companies, governments or individuals. It is important to internalise the externalities in order to reduce them. This means to make costs and benefits attributable to the individual subject to whom they belong (Jaeger, 2012).

Samuelson $(1954,1955)$ argued that the private sector does not provide public goods because there are different conditions to their effective allocation in contrast with the case of private goods. The condition for effective allocation of public goods is that the sum of the marginal rate of substitution equals the marginal rate of product transformation, i.e. the rate at which each consumer is disposed to exchange one product for another at the same level of utility equals the rate at which the economy can produce the quantity of the product at a given quantity of the other product. This contrasts private goods for which each marginal rate of substitution is equal as well as the marginal rates of product transformation. Samuelson presumes market failure as everyone selfishly pretends a lower level of utility of the public goods to avoid paying because the public goods will be allocated regardless of the contribution. Thus, the market mechanism leads to a lower allocation of public goods. Musgrave (1959) also presumes market failure and urges a central authority superior to market mechanisms to participate.

Head (1977) further expanded on Thompson's and Oakland's analysis of collective goods. Thompson (1968) presented several presumptions leading to the effective allocation of collective goods: (1) knowledge of consumers' preferences, (2) production of the goods by a monopoly, and (3) sufficient production capacities. If the monopoly knows consumers' preferences and there are sufficient production capacities, there will be an optimal quantity of the collective goods. Oakland (1974) concluded that if every subject consumes a different quantity of indivisible public goods, these quantities will have a different price based on their individual demand and supply. A pseudo-demand curve, where consumers consume the most inexpensive goods first before proceeding to more expensive ones, then represents the demand curve. On the contrary, the supply curve can be determined by the marginal costs for the public goods production as in the case of private goods. The total optimal quantity of the public goods is at the point where total marginal costs equal the price that consumers are willing to pay, i.e. where the pseudo-demand curve intersects the supply curve. However, unlike private goods, the balance is not Pareto effective. Head assumes that for public goods, non-excludability from consumption is a more serious obstacle to market balance than nonrivalry.

There are also two types of impure public goods apart from the pure ones. The first type of impure public goods is called commons. Commons are non-excludable from consumption, i.e. their consumption cannot be limited, but they are rival because their quantity is limited. Typical examples are raw material extraction or fishing. The second type of impure public goods is called club goods. Club goods are non-rival as their quantity 
is not limited but consumers can be excluded from consumption. Typical examples are private parks and satellite television. Stiglitz (2000b) suggests that a substantial majority of public goods are not pure but rather impure. Impure public goods also face the problem of effective allocation and moderation of externalities. Therefore, they are usually provided by the public sector as there would be an insufficient quantity of these goods otherwise (Stiglitz, 2000a).

Regarding the geographical scope of goods allocation, we can distinguish between regional, international, and global goods (Te Velde, Morrissey and Hewitt, 2002). Kaul and Mendoza (2002) defined global public goods as goods that are available worldwide to all socio-economic groups and to all generations. Whereas some goods are naturally global, such as air or the ozone layer, the number of goods that have been globalised is growing (Kaul, 2009). Kaul identified three types of global public goods: (1) goods where it is naturally impossible or unreasonably expensive to be excluded from consumption, such as solar radiation, (2) goods that were designed as public, such as education and the legal system, (3) goods that have become public due to a lack of knowledge or foresight, such as ozone layer depletion.

Pure global public goods have the same features as the public goods, i.e. nonexcludability from consumption and non-rivalry; however, they are globally deployed (Sandler, 2002). They also face the same problems, which are the management of externalities and effective allocation. As the social utility from global public goods is available to those who did not pay for it due to non-excludability, consumers tend to state a lower level of its utility to decrease the price (ibid.). This leads to market failure and an inefficient quantity of the goods. However, for global public goods, these problems are even more daunting. Whereas externalities on the level of nation states can be addressed by an efficient legal system, there is no such authority on the global level (Bodansky, 2013). Yet such global public goods include the environment, security, and public health, which are essential to humanity. Some international governmental and non-governmental organisations were founded to bind the states to adopt measures for externalities minimisation (Kaul et al., 2003). The debate over global public goods management constitutes a part of the issue of global governance.

Regarding global impure public goods, we can again distinguish two types - global commons and global club goods. Global club goods are the other type of global impure goods where it is possible to exclude consumers from consumption but the quantity of the goods is not limited. The excludability enables to impose a fee on consumption. The price for consumption is derived from the total utility of the consumer and marginal costs of the provider to gain another consumer. Consumers decide to pay when their costs equal the utility (Sandler and Tschirhart, 1997).

Global commons are available at the supranational level, are non-excludable but are rival, i.e. there is a limited quantity and thus limited consumption of these goods. Typical examples are oceans, the atmosphere, the universe, and Antarctica (Dauvergne, 2012). The Internet is also sometimes labelled as global commons (Raymond, 2012). As it is very difficult or rather impossible to exclude consumers from consumption of global commons, there is the peril of its excessive depletion. However, there are some differences from national-level agendas. A high number of consumers results in higher heterogeneity, cultural differences and different expectations, and complicates adopting agendas to moderate the externalities. 
Digital commons can be defined as a source of information and knowledge that is created collectively, possessed collectively, and shared collectively within an open community, and thus is accessible to a third party (Fuster and Morell, 2010). Cyberspace was created by the people and for the people with its content freely accessible and freely distributable, including information and technology. The sources in cyberspace are consumed and further maintained by the community that created them (Stadler, 2010); striking examples are the Wiki system and free software. Some authors even include these sources in the common heritage of mankind alongside language, art, culture etc. (Baslar, 1998).

Special licenses were created to prevent misuse of these freely distributable sources, e.g. the GNU licence created by Richard Stallman, which guarantees free use of these sources. Another example is the non-profit organisation Creative Commons, which provides a wide range of copyrights to digital commons contributors (Walljasper, 2010). Such copyrights are mostly used to prevent the commercialisation of digital commons.

Kaul (2012) also suggests politicising global public goods that became public due to a lack of knowledge or foresight as global commons (global goods that are non-excludable but rival as their quantity is limited) until the knowledge reaches the level at which regulation of externalities will be possible. As an example, she states potable water as it is a part of the global water cycle. If the availability of potable water depended solely on market forces, those who suffer from the lack of it the most would be those who could not afford it for the market price. Managing potable water as global commons might establish more equal conditions for those countries suffering from the lack of it.

Buchholz, Haslbeck and Sandler (1998) name three factors reducing market failure for global pure public goods allocation: (1) the number of consumers who are willing to pay for global pure public goods must be higher than the number of consumers who do not pay; (2) there must be relative consumer resistance to global pure public goods among those who do not pay; (3) consumption of global pure public goods must be higher among consumers who pay.

\subsection{Information as Global Public Goods}

Information is often described as a typical example of public goods. There is a shared perception that information is non-excludable and nonrival. The recipient of the information does not decrease the quantity of the goods; on the contrary, the recipient can only enrich the information through interaction (Herzog, 2006). Some economists (Herings and Schinkel, 2005) see information as experience goods, i.e. we can recognise the value of the goods at the time of consumption. There is also not enough stimuli to provide information in the private sector and this may lead to an insufficient amount of information on the market (Hirshleifer, 1971), which supports the notion that information is public goods.

Some economists differentiate between information and knowledge (Nilsen, 2010). Machlup (1981) perceived information only as a process of knowledge transmission. Similarly, Chichilnisky (1999) described information as a medium for knowledge transmission. On the contrary, Boulding (1966) argued that we can acquire knowledge only after selection and organisation of information, and not by a mere gathering of information. Noll (1993) sees information as a need for communication with importance for the sender and receiver, and thus it represents a form of consumption. Nevertheless, most economists 
do not address the difference between information and knowledge and perceive both as synonyms (Foray, 2004).

However, the object of discussion is the excludability of information. Boulding (1966) maintains information can be limited by legal mechanisms such as patents and trade secrets which enable possession of information. While others (Eaton, 1987; Arrow, 1985) are convinced information cannot be fully possessed which makes it pure public goods. Perceiving information as pure public goods, the problem of the undersupply of information on the market arises. The private sector would not have any incentive to produce it (Arrow, 1984; Eaton, 1987; Stiglitz 1994, 2000a, 2000b) and thus it should be in the hands of the public sector (Stiglitz et al., 2000), albeit the use of information can be limited through legal mechanisms, and thus partly possessed, cannot be ignored (Nilsen, 2010).

Another question is whether information can be termed as a commodity. If so, then its optimal price and quantity could be determined. Boulding (1966) first challenged this notion when he stated that information cannot be divided into single units. Another issue was the fact that adding the quantity of information does not necessarily lead to greater knowledge. An increase in the quantity of information might rather cause a possible change in quality and, therefore, information quantifying loses its sense. The sale and purchase of knowledge both cause complications. The seller of information does not lose anything: information is still available because it is not diminishable. The purchaser does not know the value of information until they experience it. This argument favours the possibility of terming information experience goods.

The price can be perceived as an allocation mechanism, which is determinative for the demand while costs are determinative for the supply (Simon, 1991). Price balances supply and demand and leads to an optimum level of production, whereas prices above or below marginal costs result in deadweight losses. For the nonrival feature of information, social costs should be considered to set the price more accurately (Lee, 1982).

\section{A Simplified Cyberspace Model}

By defining cyberspace as pure global public goods, global impure public goods or private goods, we must consider (1) the structure, means of functioning, and means of use of cyberspace, (2) the content of cyberspace, and (3) the features of cyberspace. Cyberspace will be divided into layers which will be further analysed to assess whether it can be termed as global public goods. A synthesis of the analysis and the answer to the research question of whether cyberspace can be called global public goods will be presented at the end.

A common feature of cyberspace definitions is the great amount of generality, which enables to include not only the physical infrastructure - hardware, software, information, users and others - but also such aspects as human interpretation of information in the category of cyberspace (Ormrod and Turnbull, 2016). One of the first models of cyberspace used in social sciences was presented by Libicki (2007) who drew inspiration from the linguistic methodology. The model works with three layers: (1) physical, (2) syntactical, and (3) semantic. (1) The physical layer is comprised of physical infrastructure and communication devices and builds an essential base for the other two layers and may have serious geopolitical consequences. Therefore, part of this layer is separated as the critical infrastructure of the state. An important fact is that it is possible 
to apply state law to this layer, which may provide governments with a certain amount of power, even though the physical structure is usually privately owned (Sheldon, 2014). (2) The syntactical layer is represented by rules and limits through which information can be processed and includes software and applications necessary for the proper functioning of cyberspace, such as system protocols and domain names. (3) The semantic layer consists of information, which is exchanged, saved or processed.

Clark (2010) presented a similar model to Libicki as he also focused on the purpose of cyberspace, i.e. processing, manipulation, and drawing of information to simplify communication and interaction among people. His model is comprised of four layers: (1) physical layer, (2) logical layer, (3) information layer, and (4) people, while he describes people and information as the focal points of cyberspace. Like Libicki, (1) the physical layer consists of a physical infrastructure enabling the creation of cyberspace, (2) the logical layer includes aspects supporting the physical platform and enabling services, and (3) the information layer is the layer where information is processed. The new level is the fourth layer: people with different interests and roles. From the economic point of view, people are consumers of cyberspace and therefore only a three-layer model will be applied.

The physical infrastructure of cyberspace is a basic precondition for its existence and is represented by a network of devices that communicate with each other using cables or wireless communication. This layer is the most tangible as it is comprised of physical objects and connected to a place, in which these objects are situated, and thus are subjected to state authority. The network is divided into single autonomous systems consisting of routers, IP networks, and devices with their own IP address. Such autonomous systems do not copy geographical borders and often intersect them. The devices are joined by IP networks connected by routers. A special ASBR router maintained by the Internet provider is placed on the border of each autonomous system. ASBR routers on the border are interconnected and can access information about the whole Internet infrastructure. Furthermore, ASBR routers communicate through BGP protocols and thus have a map of the Internet at their disposal.

While the physical layer is a network of tangible devices; the logical layer is based on platforms and applications. The Internet works and has the given features because of these. The difference between the Internet and other types of media is the interconnectedness of its aspects, which builds the basis for the logical layer. The IP address is the key aspect and enables identification of every device connected to the Internet. The IP address is represented by a numerical code issued by the Internet provider while web pages have their own IP address based on the devices in which the data is saved. The DNS system substitutes numerical codes with domain names for easier handling so that Internet users need only to remember the names of the web pages they want to surf and not their difficult numerical codes. The DNS system and IP addresses are maintained by the ICANN organisation which connects regional organisations around the world into a single global multi-stakeholder organisation.

Information as the third layer represents cyberspace content. People enter cyberspace to create, gain, save, process, and transfer the information, which can take many forms - music, video, picture, text, and metadata used for searching information (Clark, 2010). Alvin Toffler (2001) described such a platform as infosphere, which was supposed to be the essence of a new civilisation type based on communication and knowledge. According to Toffler, knowledge will become the major production factor, forcing out the standard production factors - land, labour and capital. 


\section{Application of Global Public Goods Theory to Cyberspace}

By terming goods as global public goods, we shall answer following questions:

(1) Are the goods available globally to relatively all socio-economic groups and generations (Kaul and Mendoza, 2002)?

(2) Are the goods nonrival?

(3) Are the goods non-excludable?

(4) Who possesses the goods?

First, we must consider the worldwide physical Internet infrastructure to answer whether cyberspace is global goods. The digital divide discussion addresses the differences in information and communication technology access (Compaine, 2001) and forms a part of the global divide debate (Norris, 2001). The International Telecommunication Union addresses the digital divide focusing on subjects - such as individuals, institutions and countries connecting to the Internet - as well as the means, such as fixed broadband or mobile connection and the quality - its effectivity, reliability, and speed of the connection (Hilbert, 2011). Graphs 1 and 2 show that the worldwide average of the Internet connection is $53.6 \%$; thus, we could assess the Internet as rather global. However, there are vast differences among age groups and regions. The percentage of connection in developed countries reaches $84.4 \%$, while in developing countries it only accounts for $14.7 \%$ (ITU, 2017). Nevertheless, regarding the high proportion of young people using the Internet in developing countries, the future situation is expected to become more equal.

\section{Graph 1 | Percentage of Households Connected to the Internet in 2017 in various regions}

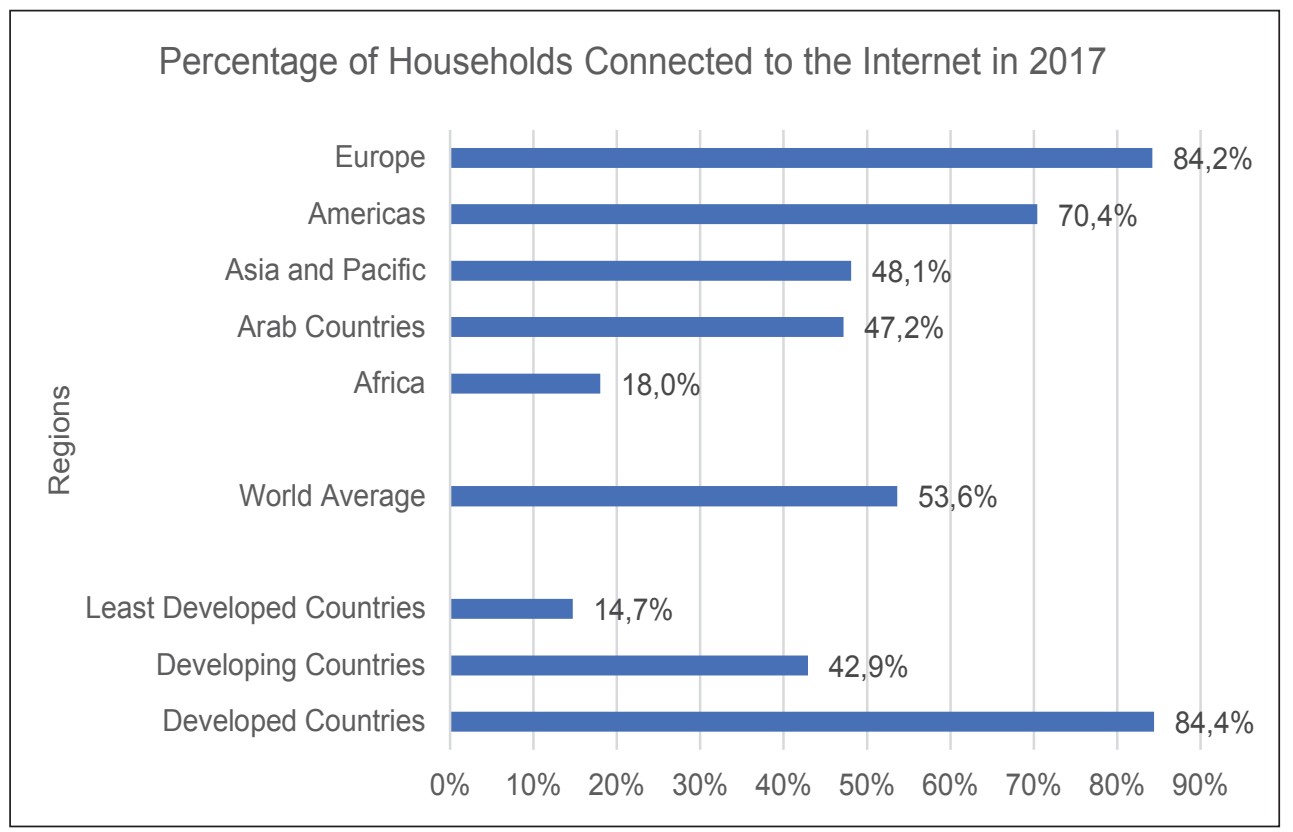

Source: (ITU, 2017) 


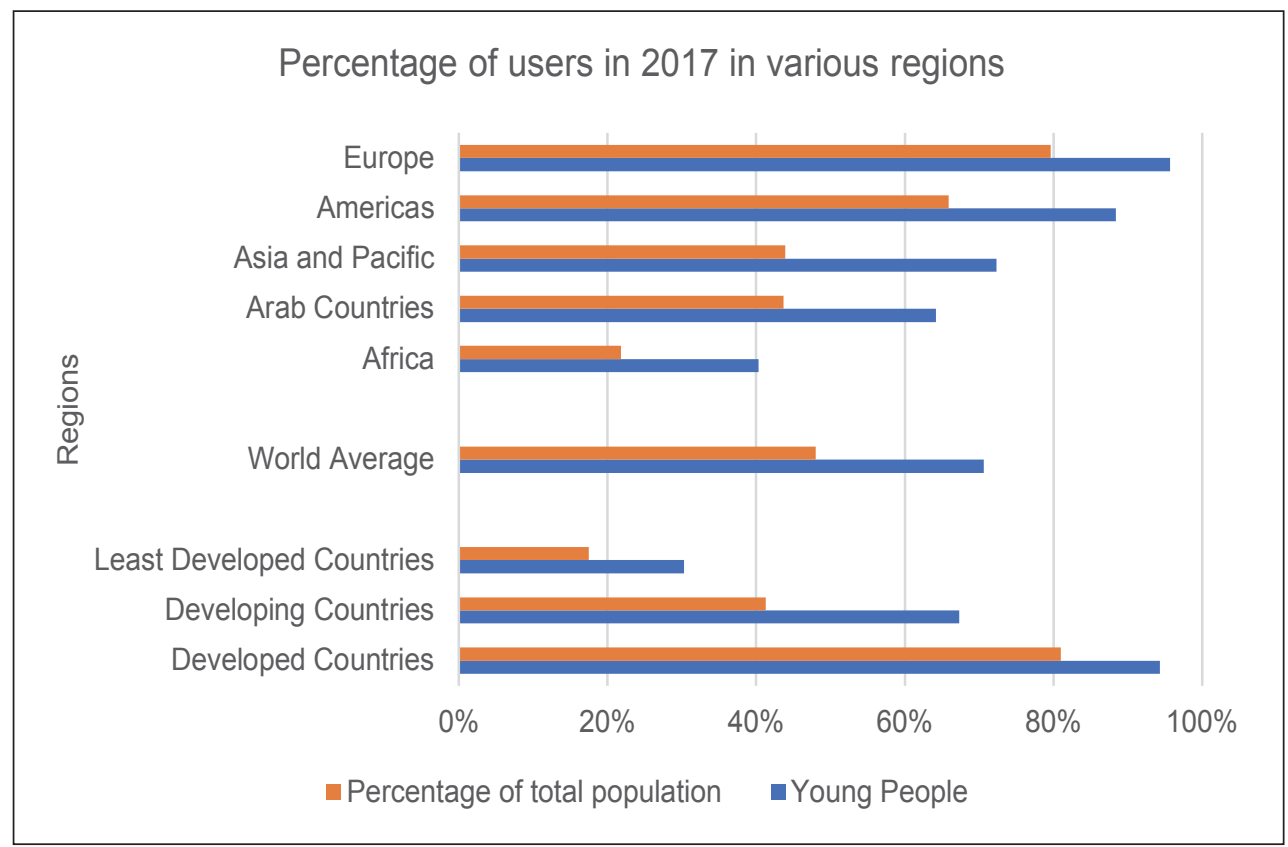

Source: (ITU, 2017)

Second, describing the physical layer of cyberspace as nonrival, the connection of one user must not limit the connection of another user. Devices connect to a router and share the speed of the connection with each other. If the number of devices connected to a router grows, the speed of connection declines relatively. However, the Internet service provider is usually obliged to provide a minimum connection speed and thus we cannot describe cyberspace as rival. Of course, the user must pay if requiring a higher connection speed.

Third, the Internet cannot be determined as non-excludable as it is possible to deny access to a user. (1) A user needs a functional device to connect to the Internet, and (2) the Internet service provider only grants access to paying users. On the other hand, it is possible to use a free public Wi-Fi connection in some public places and institutions. To conclude, the majority of the physical layer of the Internet stays excludable, even though there are limited possibilities to connect freely.

Fourth, the possession of the physical infrastructure is mostly private. The state usually regulates operation and only sets limits on the private sphere and its authority is constrained. However, the Internet has become linked to all types of infrastructures posing the risk of cyberattacks due to the Internet of Things - devices connected directly to the Internet. Therefore, some sections of cyberspace have become part of the critical infrastructure operated by the government, usually by the Ministry of the Interior (Simon, 2017). In the case of the European Union, the European Programme for Critical Infrastructure Protection was issued by the Commission in 2006 binding the members of the European Union to abide by it (EC, 2007). 
To conclude, the physical layer of cyberspace can be termed global with the reservation of unequal access for social and age groups. The physical layer is also generally privately owned with the exception of the critical infrastructure sections. It is nonrival as the speed of the users' connection does not diminish with the number of connected users due to the minimum speed provided by the Internet provider. It may be called excludable - access can be prevented to some users - but there are limited options available for users to connect to the Internet without paying in some public places or in some institutions. Therefore, it is quite difficult to assess whether this layer may, or may not, be called public goods. Nevertheless, it seems legitimate to evaluate this layer as impure public goods, more specifically club goods, as it is non-rival and rather excludable.

The second layer of cyberspace consists of applications enabling information transmission and management. As previously mentioned, the basic component of this layer is an IP address, which is automatically provided by the Internet service provider. This system works globally and is managed by the ICANN organisation, which invites users from all around the world to participate in their organisational structures. It can thus be stated that this layer is definitely global although its application depends on the availability of the physical layer.

The nonrivalry of IP addresses is disputable. There is a definite number of them, so it could become competitive. However, the Internet Engineering Task Force has already dealt with the problem of finiteness and initiated a change in communication protocols to increase the number of available IP addresses. Nowadays, there are two types of communication protocols and the number of IP addresses highly exceeds the demand, therefore, becoming nonrival goods.

IP addresses are non-excludable as they are automatically assigned. In addition, it is also possible to install software that can exchange the assigned IP address for a random one thereby reducing any level of possible discrimination of the device in cyberspace. Not only IP addresses but other free applications are also non-excludable, except for applications that have been banned in some countries or chargeable applications that can exclude users because of the high price.

The IP address service is used worldwide and freely and there are also other applications necessary for Internet operation, such as Internet browsers. These applications are privately owned by companies or individuals but are usually provided free of charge. The profits of these companies or individuals are generally yielded by advertising and data mining, especially in case of the Internet of Things (Chen et al., 2015). The data gained through the Internet of Things has high business value and is further traded in packages that form a user's personal profile.

The character of the third layer of cyberspace - information - has already been described in Chapter 1.2. Information is purely nonrival: its consumption can edit or enrich it but not diminish it. Therefore, many economists view information as experience goods and information in cyberspace is no exception to this rule. Users generate, share and consume information in cyberspace freely by their own accord. Adding to this notion, the global character of information also relates to it. It is rather expensive and demanding to limit the scope of information to a specific region and usually, only a few information categories are restricted, such as information connected with illegal activities or politically sensitive information in some nation states. 
However, the non-excludability, as well as the possession of information, poses some discrepancies as these can be limited by tools such as licenses, patent rights, etc. This is also reflected in cyberspace, circumscribing paid or extra content to some users only. Furthermore, the existence of the Darknet - the part of the Internet which is not accessible in a standard manner through Internet browsers - enables users to access and share sensitive information, often of an illegal character, between each other using specific software. On the contrary, classified information, such as bank data or personal data, represents another exclusive group of information. Nevertheless, in general, the layer of information can still be described as pure global public goods.

Table 1 | The results of the analysis applied to all layers of the cyberspace model

\begin{tabular}{|l|c|c|c|c|c|}
\hline & $\begin{array}{c}\text { Worldwide } \\
\text { accessibility }\end{array}$ & Nonrivalry & $\begin{array}{c}\text { Non- } \\
\text { excludability }\end{array}$ & Ownership & Type of goods \\
\hline $\begin{array}{l}\text { The layer } \\
\text { of information }\end{array}$ & \multirow{2}{*}{$\begin{array}{l}\text { The layer } \\
\text { of application }\end{array}$} & Nonrival & Non-excludable & Public & $\begin{array}{c}\text { Global public } \\
\text { goods }\end{array}$ \\
\cline { 1 - 4 } $\begin{array}{l}\text { The physical } \\
\text { infrastructure }\end{array}$ & Nonrival & Non-excludable & Private & $\begin{array}{c}\text { Global public } \\
\text { goods }\end{array}$ \\
\cline { 3 - 6 } & & Nonrival & Excludable & Private & $\begin{array}{c}\text { Global club } \\
\text { goods }\end{array}$ \\
\hline
\end{tabular}

Source: Author

\section{Conclusion}

This analysis has focused on answering the question of whether cyberspace can be described as global pure public goods, global impure public goods or private goods. First, economic theories discussing public goods have been presented, building basic grounds for further analysis. For the purpose of analysis, a simple model of cyberspace was adopted. The model assumes cyberspace to consist of three layers: (1) the physical infrastructure, (2) the application layer, and (3) the layer of information. Furthermore, the criteria for consequent analysis were based on these theories and questioned each layer of cyberspace. These criteria were: (1) the global character of cyberspace, (2) the nonrivalry of cyberspace, (3) the non-excludability of cyberspace, and (4) ownership of the goods.

Regarding the statistical data from the International Telecommunication Union, the physical infrastructure of cyberspace should be considered global with worldwide accessibility exceeding $50 \%$. Nevertheless, it fails to be fully accessible to all socioeconomic groups and to all generations around the world. It can be considered nonrival because the connection of one user to the Internet does not limit the possibility or quality of the connection of other users. The physical layer is excludable by demanding payment for connection to it by the Internet service provider. The physical infrastructure is also usually privately owned apart from those sections that belong to the critical infrastructure 
operated by the government. The first layer of cyberspace has been assessed as global impure public goods - namely global club goods - as it is nonrival but rather excludable.

For the second layer of applications, IP addresses were discussed. This layer was assessed as rather nonrival as acquiring an IP address does not prevent other users from gaining theirs and there is an excessive number of available IP addresses to be used. The application layer is considered non-excludable: the system of IP addresses works globally and is operated by the ICANN global multi-stakeholder organisation which invites all users to participate in its structures. However, the possibility of using the services of this layer largely depends on access to the physical layer. Thus, it can be described as global public goods. Even though the applications and services of this level are privately owned, they are generally provided free of charge. The second layer has thus been assessed as global public goods.

In addition, the third layer of information, which can also be termed global public goods for information, is naturally nonrival - the consumption of information does not decrease the utility of another user although it may even enhance it. It is technologically and economically highly demanding to exclude a subject from its consumption, and so it can be seen as non-excludable. The ownership of information is rather disputable too. Information can be possessed through patents or licenses but it cannot be applied to all pieces of information. Finally, due to cyberspace, information can nowadays be accessed globally.

Based on the analysis, it is arguable whether cyberspace may be assessed as global public goods: each of the layers of cyberspace is unique and shows distinctive features. The physical layer represents global impure public goods, whereas the layer of applications and the layer of information proved to be global public goods - for a summarising graphic presentation see Table 1. Due to the possibility of acquiring access to the Internet in some public places, and thus make the physical layer non-excludable. I personally lean towards the notion that cyberspace can be labelled global public goods.

Cyberspace enables communication across the entire world, sharing, and exchanging information. It is also becoming increasingly independent of standard regulators such as states and financial groups. However, with the rise of cyberattacks and the connectivity of cyberspace with other infrastructures, some sections of the physical layer identified as critical infrastructure are falling within the power of governments. The safety of cyberspace represents a vital issue and must not be underestimated.

\section{References}

Arrow, K. J. (1984). Information and Economic Behavior [Lecture presented to the Federation of Swedish Industries, Stockholm, 1973]. In: Collected Papers of Kenneth J. Arrow, Vol. 4. Cambridge, MA: Harvard University Press, pp. 136-152.

Arrow, K. J. (1985). Economic Welfare and the Allocation of Resources for Invention. In Collected Papers of Kenneth J. Arrow, Vol. 5. Cambridge, MA: Harvard University Press, pp. 104-119.

Baslar, K. (1998). The Concept of the Common Heritage of Mankind in International Law. Martinus Nijhoff Pubs.

Bodansky, D. (2013). The Who, What, and Wherefore of Geoengineering Governance. Climatic Change, 121(3), pp. 539-551, https://doi.org/10.1007/s10584-013-0759-7 
Boulding, K. E. (1966). The Economics of Knowledge and the Knowledge of Economics. The American Economic Review, 56(1/2), 1-13.

Buchholz, W., Haslbeck, C. and Sandler, T. (1998). When Does Partial Cooperation Pay? FinanzArchiv, 55(1), pp. 1-20.

Chen, F., Deng, P., Wan, J., Zhang, D., Vasilakos, A. V. and Rong, X. (2015). Data Mining for the Internet of Things: Literature Review and Challenges. International Journal of Distributed Sensor Networks, 11(8), https//doi.org/10.1155/2015/431047

Clark, D. D. (2010). Characterizing Cyberspace: Past, Present and Future. [online] MIT CSAIL. Available at: http://docshare01.docshare.tips/files/9608/96080638.pdf [Accessed 20 Jan. 2018].

EC (European Commission), (2007). Communication from the Commission of 12 December 2006 on a European Programme for Critical Infrastructure Protection. Official Journal C 126 of 7.6.2007.

Compaine, B. M. (2001). The Digital Divide: Facing a Crisis or Creating a Myth? Cambridge, MA: MIT Press.

Dauvergne, P. (2012). Handbook of Global Environmental Politics. 2nd ed. Cheltenham, UK: Edward Elgar Publishing.

Eaton, J. J. (1987). Is Information a "Resource"? A Review of the Literature Relating to the Economic Significance of Information. MA. Department of Information Studies, Sheffield University.

Foray, D. (2004). Economics of Knowledge. Cambridge, MA: MIT Press.

Fuster Morell, M. (2010). Governance of Online Creation Communities: Provision of Infrastructure for the Building of Digital Commons. PhD. European University Institute.

Head, J. G. (1962). Public Goods and Public Policy. Public Finance, 17(3), pp. 197-219.

Head, J. G. (1977). Public Goods: The Polar Case Reconsidered. Economic Record, 53(2), pp. 227-238, https://doi.org/10.1111/j.1475-4932.1977.tb01611.x

Herings, P. J.-J. and Schinkel, M. P. (2005). World-Wide-Welfare: A Micro-analysis of "The New Economy." In: L. Soete and B. Weel, eds., The Economics of the Digital Society, 1st ed. Cheltenham, UK: Edward Elgar, pp. 14-53.

Herzog, P. (2006). Services of General Interest in a Competitive Multinational Space. In: J.-P. Touffut, ed., Advancing Public Goods: Papers from the 6th Conference of the Cournot Centre for Economic Studies, 1st ed. Cheltenham, UK: Edward Elgar, pp. 69-103.

Hilbert, M. (2011). The End Justifies the Definition: The Manifold Outlooks on the Digital Divide and Their Practical Usefulness for Policy-making. Telecommunications Policy, 35(8), pp. 715-736, https://doi.org/10.1016/j.telpol.2011.06.012

Hirshleifer, J. (1971). The Private and Social Value of Information and the Reward to Inventive Activity. American Economic Review, 61(4), pp. 561-574.

Chichilnisky, G. (1999). Introduction. In: G. Chichilnisky, ed., Markets, Information and Uncertainty: Essays in Economic Theory in Honor of Kenneth J. Arrow, 1st ed. New York: Cambridge University Press, pp. 13-18.

ITU (International Telecommunications Union), (2017). ICT Facts and Figures. [online] Available at: https://www.itu.int/en/ITU-D/Statistics/Pages/facts/default.aspx [Accessed 13 Feb. 2018].

Jaeger, W. (2012). Environmental Economics for Tree Huggers and Other Skeptics. Island Press. 
Kaul, I. and Mendoza, U. (2003). Advancing the Concept of Public Goods. In: I. Kaul et al., eds., Providing Public Goods: Managing Globalization, 1st ed. Oxford: Oxford University Press, pp. 101-134.

Kaul, I. et al, eds. (2003). Providing Global Public Goods: Managing Globalization. Oxford: Oxford University Press.

Kaul, I. (2009). Global Public Goods. In: The Princeton Encyclopedia of the World Economy, 1st ed. Princeton University Press, pp. 550-554.

Kaul, I. (2012). Rethinking Public Goods and Global Public Goods. In: E. Brousseau, T. Dedeurwaerdere and B. Siebenhüner, eds., Reflexive Governance for Global Public Goods, 1st ed. Cambridge, MA: MIT Press, pp. 37-54.

Lee, D. R. (1982). On the Pricing of Public Goods. Southern Economic Journal, 49(1), pp. 99-105, https://doi.org/10.2307/1058545

Libicki, M. C. (2007). Conquest in Cyberspace: National Security and Information Warfare. New York: Cambridge University Press.

Macáková, L. (2006). Veřejné statky [Public Goods]. In: B. Hořejší, J. Soukupová, L. Macáková and J. Soukup, eds., Mikroekonomie [Microeconomics], 1st ed. Prague: Management Press.

Machlup, F. (1981). Knowledge: Its Creation, Distribution, and Economic Significance. Volume I.: Knowledge and Knowledge Production. Princeton, NJ: Princeton University Press.

Mcconnell, C., Brue, S. and Flyn, S. (2008). Macroeconomics. McGraw-Hill Economics.

Musgrave, R. A. (1959). The Theory of Public Finance: A Study in Public Economy. New York: McGraw-Hill.

Nilsen, K. (2010). Economic Theory as It Applies to Public Sector Information. Annual Review of Information Science and Technology, 44(1), pp. 419-489, https://doi.org/10.1002/aris.2010.1440440117

Noll, R. G. (1993). The Economics of Information: A User's Guide. In: The Knowledge Economy: The Nature of Information in the 21st Century. Institute for Information Studies. Queenstown, MD: Aspen Institute, pp. 29-30.

Norris, P. (2001). Digital Divide: Civic Engagement, Information Poverty, and the Internet Worldwide. New York: Cambridge University Press.

Oakland, W. H. (1974). Public Goods, Perfect Competition, and Underproduction. The Journal of Political Economy, 82(5), pp. 927-939, https://doi.org/10.1086/260247

Ormrod, D. and Turnbull, B. P. (2016). The Military Cyber-Maturity Model - Preparing Modern Cyber-Enabled Military Forces for Future Conflicts. In: Proceedings of 11th International Conference on Cyber Warfare and Security. Boston: Boston University.

Raymond, M. (2012). The Internet as a Global Commons? [online] The Centre for International Governance Innovation. Available at: https://www.cigionline.org/publications/internet-global-commons [Accessed 2 Feb. 2018].

Samuelson, P. A. (1954). The Pure Theory of Public Expenditure. The Review of Economics and Statistics, 36(4), pp. 387-389, https://doi.org/10.2307/1925895

Samuelson, P. A. (1955). Diagrammatic Exposition of a Theory of Public Expenditure. The Review of Economics and Statistics, 37(4), pp. 350-356, https://doi.org/10.2307/1925849

Sandler, T. (2002). Financing International Public Goods. In: M. Ferroni and A. Mody, eds., International Public Goods, 1st ed. Springer, pp. 81-117.

Sandler, T. and Tschirhart, J. (1997). Club Theory: Thirty Years Later. Public Choice, 93(3/4), pp. 335-355, https://doi.org/10.1023/A:1017952723093 
Sheldon, J. B. (2014). Geopolitics and Cyber Power: Why Geography Still Matters. American Foreign Policy Interests, 36(5), pp. 286-293, https://doi.org/10.1080/10803920.2014.969174

Simon, H. A. (1991). Organization and Markets. Journal of Economic Perspectives, 5(2), pp. 25-44, https://doi.org/10.1257/jep.5.2.25

Simon, T. (2017). Critical Infrastructure and the Internet of Things. [online] Global Commission on Internet Governance Paper Series: No. 46. Available at: https://www.cigionline.org/sites/default/files/documents/GCIG\%20no.46_0.pdf [Accessed 22 Feb. 2018].

Stalder, F. (2010). Digital Commons. In: K. Hart, J.-L. Laville and A. D. Cattani, eds. The Human Economy: A World Citizen's Guide. Cambridge: Polity Press, pp. 313-324.

Stiglitz, J. E. (1994). Whither Socialism? Cambridge, MA: MIT Press.

Stiglitz, J. E. (2000a). The Contributions of the Economics of Information to Twentieth Century Economics. The Quarterly Journal of Economics, 115(4), pp. 1441-1478, https://doi.org/10.1162/003355300555015

Stiglitz, J. E. (2000b). Economics of the Public Sector. 3rd ed. New York: W. W. Norton.

Stiglitz, J. E., Orszag, P. R. and Orszag, J. M. (2000). The Role of Government in a Digital Age. Washington, DC: Computer and Communications Industry Association.

Te Velde, D. W. Morrissey, O. and Hewitt, A. (2002). Allocating Aid to International Public Goods. In: M. Ferroni and A. Mody, eds., International Public Goods, 1st ed. Springer, pp. 119-156.

Toffler, A. (1980). The Third Wave. New York: William Morrow and Company.

Walljasper, J. (2010). All That We Share: How to Save the Economy, the Environment, the Internet, Democracy, Our Communities, and Everything Else That Belongs to All of Us. New York: The New Press. 